\title{
Diverse effects of diversity: Disaggregating effects of diversity in global virtual teams
}

\author{
Vas Taras, Daniel Baack, Dan Caprar, Douglas Dow, \\ Fabian Froese, Alfredo Jimenez, Peter Magnusson
}

\begin{abstract}
Global Virtual Team (GVT) member diversity provides many advantages but also poses many challenges. Diversity comes in different forms that each have different effects on GVT dynamics and performance. Past research typically explored the effect of only one type of diversity at a time. Using multi-source, multi-wave data from 5,728 individuals working in 804 consulting project GVTs, the present study is unique in that it explores and compares the effects of different forms of team member diversity on different aspects of GVT effectiveness in a single sample. It proposes a refined theoretical model that differentiates between the effects of personal versus contextual diversity and articulates how these distinct forms of diversity affect different aspects of GVT effectiveness (i.e., task outcomes versus psychological outcomes). The results reveal that (1) team member diversity in general has a substantial effect on GVT effectiveness; (2) contextual diversity has a positive effect on task outcomes; and (3) personal diversity has a negative effect on psychological outcomes. Implications for practice and future research are discussed.
\end{abstract}




\section{INTRODUCTION}

Technological development and greater global integration have led to an unprecedented rise of global virtual collaboration in the workplace (Chudoba, Wynn, Lu, \& Watson-Manheim, 2005; Martins, Gibson, \& Maynard, 2004). Experts estimate that approximately $60 \%$ of managers regularly complete tasks as members of geographically dispersed virtual teams (Hertel, Geister, \& Kondradt, 2005) and, more recently, that "corporate teams are now almost entirely virtual" ( $\mathrm{RW}^{3}$ CultureWizard, 2016, p. 3). Due to an accelerated rate of internationalization coupled with the development of online collaboration technologies, organizations are increasingly employing global virtual teams (GVTs).

A GVT have been defined as a "temporary, culturally diverse, geographically dispersed, and electronically communicating work group" (Jarvenpaa \& Leidner, 1999, p. 792) or as a team whose members are separated by time and space, and differ in national, cultural, and linguistic attributes, and whose functioning is heavily dependent on computer-mediated technologies (Zakaria, 2009). GVTs offer several potential advantages. First, by removing the need for and costs associated with being physically present in a certain location, teams can be staffed with experts from around the globe. Second, drawing on the diversity of perspectives and resources brought in by their members, GVTs have the potential for increased creativity and enhanced problem solving. Third, the "sun never sets" in GVTs and the workload can be handed off seamlessly from one time zone to the next (e.g., Duckworth, 2008). However, despite many potential benefits, GVTs also face substantial obstacles. Differences in language, culture, and institutional environments come with increased coordination costs and information-processing losses, ultimately limiting team effectiveness (Maznevski \& Chudoba, 2000; Montoya-Weiss, Massey, \& Song, 2001).

This mix of inherent advantages and obstacles prompts the following question: Is GVT diversity "good" or "bad" for team effectiveness? To date, "research on the relationship between work group diversity and performance has yielded inconsistent results" (van Knippenberg, De Dreu \& Homan, 2004, p. 1008). Efforts to integrate the team diversity literature have been made (e.g., Stahl, Maznevski, Voight, \& Jonsen, 2010); yet, the extant literature does not provide definitive answers or clear guidance to managers. This is problematic given the increased use of GVTs by many organizations, and a strong desire by managers to understand how GVT performance can be optimized (Jiménez, Boehe, Taras, \& Caprar, 2017).

Earlier research on the effects of diversity in teams is subject to several notable limitations. First, the operationalization of diversity has typically been limited to simple 'surface-level' categories, such as gender, age, race and/or citizenship (e.g., Baugh \& Graen, 1997; Ely, 2004; Harrison, Price, \& Bell, 1998), while less visible types of differences tended to be overlooked. Second, prior research has often been based on in-classroom simulations where teams completed relatively simple and short activities. The time for these was often limited from just a few minutes to a few hours (e.g., Cox, Lobel, \& McLeod, 1991; Watson, Kumar, \& Michaelson, 1993). Such experiments tend to be a poor reflection of organizational management and reward structures. Third, some studies have simulated cultural differences and geographic dispersion through scenario playing, or priming, which could have masked true effects (Oyserman, Coon, \& Kemmelmeier, 2002). Fourth, team effectiveness is a complex construct, and team member diversity may affect each of its different facets in separate ways (e.g., Bleijenbergh et al. 2010; Milliken \& Martins, 1996; Webber \& Donahue, 2001). Fifth, prior studies tended to focus on a specific single type of diversity, which made it impossible to compare the effects of different types of diversity, spare a few very rare attempts when such comparisons were made by the means of a meta-analysis (e.g., Stahl et al, 2010). 
This study aims to overcome these limitations by doing the following: (1) simultaneously examining and comparing a more comprehensive set of different types of diversity, (2) using a large sample of GVTs (5,728 participants working in 804 GVTs) that worked together for a substantial period of time (on average 2 months), and (3) considering the effects of diversity on both supervisor-rated team performance (task outcomes) and personal evaluation of satisfaction (psychological outcomes). Furthermore, based on our review of the GVT literature, we develop an integrated theoretical model that explains when the effects of team diversity are expected to be positive, negative, or non-significant. Thus, our conceptual model and empirical analysis provide a framework to think about the effects of different types of diversity on different aspects of team effectiveness and offer actionable advice for practitioners.

We purposely cast a wide net of diversity indicators to achieve a richer understanding of how different types of diversity affect team effectiveness. There are many types of team member diversity, and it seemed necessary and useful to test their comparative effects in a single sample. This approach is supported by, for example, Hambrick (2007, p. 1346), who argued that "papers that identify compelling empirical patterns that cry out for future research and theorizing" are valuable, and by Cantwell, Dunning, and Lundan (2010, p. 573) who suggest this approach can serve as an "analytical bridge between empirical investigation and formal models."

We proceed with a review of the literature on the effects of GVT diversity on team effectiveness. Next, we propose a theoretical model that differentiates between personal and contextual diversity, and also distinguishes between teams' outputs, such as the quality of the product produced by the team, and psychological outcomes, such as team member satisfaction. We then test our theoretical model and review the results which lead to new insights regarding the impact of diversity on GVT effectiveness. We conclude with a discussion of the implications of our findings, limitations, and suggestions for future research.

\section{LITERATURE REVIEW AND THEORY BUILDING}

The extant literature conflicts regarding the relationship between team member diversity and team effectiveness. Some studies found a negative effect (Earley \& Mosakowski, 2000; Thomas, Ravlin, \& Wallace, 1996), while others found the opposite (for reviews see Horwitz \& Horwitz, 2007; Kirkman \& Shapiro, 2005). Several literature reviews have addressed the issue of the conflicting conclusions about the effects of team diversity, but they focused on the effects of top management team diversity (Nielsen, 2010), board diversity (McMahon, 2010), or the demographic diversity of the employees in general (Williams \& O'Reilly, 1998), and their effects on firm performance (Robertson, Holmes, \& Perry, 2017). The goal of the present study is to explore whether the conflicting evidence is due to the failure of earlier research to recognize that different types of diversity affect team effectiveness differently, particularly in the context of GVTs.

By definition, a GVT is subject to multiple types of team-member differences, which may include demographic, cultural, geographic, economic and institutional variables (Townsend, DeMarie, \& Hendrickson, 1998). We propose that different types of team member diversity may have different effects on different aspects of team effectiveness. Specifically, with respect to diversity, our model differentiates between personal diversity among the team members and the diversity of contexts that the team members represent. With respect to team effectiveness, our model differentiates between quality of the task performance and psychological outcomes. 
We define personal diversity as differences pertaining to the personal characteristics or perceptions of the team members. These include diversity based on age, gender, language skills, technical skills, personal values, and cultural intelligence. In contrast, contextual diversity is defined as differences in the characteristics of the contexts and environments that the team members represent, have access to, or come from. This includes diversity based on economic development, human development, income inequality, corruption, importance of religion, etc.

The distinction between personal versus contextual diversity echoes the earlier differentiation made between surface-level and deep-level diversity by Stahl et al. (2010). However, some important differences merit highlighting. First, Stahl et al. (2010) focused specifically on cultural diversity and its manifestation at the visible (surface) versus invisible (deep) levels. We advance the discussion by examining a broader range of inter-member diversity in teams. Diversity is not only cultural, but it also includes demographics and various characteristics of team members' national environments and contexts they represent, understand, or can utilize. We go beyond visible and invisible characteristics of the person and, differentiate between characteristics of the person and characteristics of the contexts the team members bring to the team. Based on their meta-analysis, Stahl et al. (2010) concluded that cultural diversity leads to process losses through task conflict and decreased social integration, but also leads to process gains through increased creativity and satisfaction. To better explain this conclusion, they refined their model by differentiating between intra-national versus crossnational diversity dimensions, hypothesizing that cross-national diversity will have a positive effect on team creativity and a negative effect on team communication effectiveness. Their theoretical conceptualization was not fully supported by their data. More specifically, their results revealed no differences in performance in intra- versus cross-national teams.

Further, our model offers a more fine-grained examination of team effectiveness, as it categorizes GVT effectiveness into two distinct categories: task outcomes and psychological outcomes (c.f., Abbas, Raja, Darr, \& Bouckenooge, 2014; de Cuyper, Castanheira, White, \& Chambel, 2014). Task outcomes are defined as the objective results of teamwork. This facet includes such aspects as quality and innovativeness of team output, as evaluated by external managers or supervisors. Psychological outcomes pertain to the social and psychosocial result of teamwork, such as team member satisfaction and psychological well-being of the team members during and after the project is completed (Hackman, 1987). The connection between the personal and context diversity dimensions and task outcomes and psychological outcomes of the team effectiveness can be described by a $2 \times 2$ matrix, which we present in Figure 1.

Insert Figure 1 about here

In the next section, we review the theoretical arguments and empirical evidence in support of a negative effect of diversity. An examination of the theoretical arguments and empirical evidence supporting a positive view of diversity follows. By integrating and refining previous theoretical contributions, we propose an integrative theoretical model for when and why different forms of diversity may have opposite effects on different measures of GVT effectiveness.

\subsection{Negative Effects of Diversity}

In the international business (IB) literature, a large body of work has focused on the effects of distance between, for example, home and host market, buyers and sellers, JV partners, etc. A general assumption in this literature is that distance implies barriers, 
difficulties, costs, and risks (Shenkar, Luo, \& Yeheskel, 2008). Indeed, a recent review revealed that almost $95 \%$ of the 1,141 studies that investigated distance posited negative theoretical assumptions about its effects (Stahl \& Tung, 2014). Similarly, in GVTs, diversity presents barriers to collaboration. Separation in physical space, linguistic barriers, and cultural differences can inhibit communication and coordination among the team members (Zakaria, 2017). This in turn undermines the team's ability to effectively complete its tasks. Simply put, it is more challenging to work together when you do not speak the same language, have different values, and follow different schedules.

Two related social psychology theories predict why diversity may have negative effects. The similarity-attraction theory postulates that people tend to associate with others who are similar to them, both socially and professionally. Similarity on easily observable attributes such as race, ethnicity, origin or social status, and on subtler attributes such as attitudes and beliefs, creates real or perceived familiarity, which leads to a sense of comfort, closeness, and efficiency in interaction (Kirkman, Rosen, Tesluk, \& Gibson, 2004; Magnusson, Schuster, Taras, 2014; O'Grady, Lane, 1996; Thomas, 1999). Similar reasoning can be made drawing on social identity theory (Tajfel, 1974; Vahtera et al. 2017). Social identity theory suggests that individuals depend on protection from the group. As such, people identify themselves as members of specific groups and categorize others as members or non-members of those groups based on a range of attributes, including visible and perceived similarities (Haas, 2010). To show group loyalty, people tend to treat those in the in-group with favoritism and those in the out-group with prejudice. Thus, as a consequence of the social categorization, social identity and social comparison processes taking place within teams, diversity leads to group fragmentation and subgroup rivalry, inhibiting communication and cooperation across members belonging to different categories.

Putting these theories together, it can be concluded that personal homogeneity leads to inter-member attraction, closeness, and efficiency in communication, which in turn facilitates group integration and cohesion. In contrast, team heterogeneity has the opposite effect (Williams \& O’Reilly, 1998). Therefore, we hypothesize that:

\section{Hypothesis 1: Personal diversity among team members will have a negative effect on} a) task outcomes and b) psychological outcomes.

Further, we expect the effects of the personal differences to relate more strongly to psychological outcomes than to task outcomes. That is, we expect that personal diversity will have a negative effect on both facets of team effectives, but the effect will be relatively weak on task outcomes, and comparatively stronger on psychological outcomes. Our reasoning is an extension of Stahl and colleagues' (2010) model, according to which deep-level diversity aids team creativity, whereas the effects of surface-level diversity, which fits within our concept of personal diversity, are limited primarily to interpersonal processes, such as conflict, communication, or satisfaction. The underlying logic is that personal diversity primarily affects interpersonal interactions. It impedes communication, reduces attraction among the team members, and often is associated with biases and prejudices. Thus, it has a negative effect on, first and foremost, the psychological aspects of teamwork, such as reduced team cohesion, satisfaction with team members and the project in general. The task outcomes may also be adversely affected, but less proximally and to a lesser degree. Therefore, we hypothesize that: 


\section{Hypothesis 2: Personal diversity among team members will have a stronger negative effect on psychological outcomes than on task outcomes.}

\subsection{Positive Effects of Diversity}

Stahl, Tun, Kostova, \& Zellmer-Bruhn (2016, p. 621) recently noted that "research in IB may have overly emphasized a negative view on distance and diversity of all kinds." Indeed, a growing body of research finds that team diversity can improve team performance (e.g., Earley \& Mosakovski, 2000), in particular via increased creativity (O’Reilly, Williams, \& Barsade, 1998) and innovation (Lisak, Erez, Sui \& Le, 2016). Indeed, diverse backgrounds of team members can create value by allowing for diversity of perspectives and adaptability, which, in turn, allows for tapping a wider range of information sources, feeding off more networks, and thus aiding creativity and problem solving (DiStephano \& Mazneski, 2000; Ng \& Tung, 1998).

The positive effects of diversity can be explained by information processing theory (Simon, 1978) and the resource-based view (Barney, 1991). According to the information processing theory, a large pool of information and a variety of perspectives aid problem solving, facilitate creativity, innovation, and adaptability (Simon, 1978). Diverse team members come from diverse contexts and thus have access to diverse knowledge. This allows them to generate alternative and unique viewpoints, which motivates consideration of a larger number of possibilities and solutions (William \& O'Reilly, 1998). Homogeneity, in contrast, limits the team's ability to understand different contexts and access different pools of resources. As a result, homogeneity may lead to "groupthink," conformity, and narrow-mindedness (Janis, 1982). This hampers effective decision-making, creativity, and innovation (Jackson, 1992; Nemiro, 2002; Watson, Kumar \& Michaelsen, 1993).

Further, the resource-based view (RBV) suggests that the more heterogeneous the resources, the more difficult they are to copy or substitute, and consequently the more valuable and instrumental to team success (Janis, 1982; Shaw \& Barrett-Power, 1998). Diversity increases the chance of getting access to new learning opportunities and sources (Wernerfelt, 1984). It also broadens the pool of cognitive resources, knowledge and perspectives to which the team has access, which aids problem solving (Cox, Label, \& McLeod, 1991). Moreover, diversity not only increases the heterogeneity of tangible and intangible resources the team members have access to, but also allows for more ways to combine these resources, which boosts the team's potential (Van Knippenberg, De Dreu, \& Homan, 2004). Furthermore, diversity aids what Roberson and colleagues (2017) call "alliancing." That is, more diverse teams have access to more potential partners for voluntary exchange of information and resources, as well as being better positioned to effectively manage multiple alliances and partnerships. What makes these resources especially valuable is, unlike personal skills and knowledge, resources associated with this kind of contextual diversity are hard to replicate.

It is also important to keep in mind that contextual diversity does not necessarily have to follow national borders. If the team members come from different countries, but the countries have similar institutional and cultural characteristics, then the international nature of the team will have little effect on team effectiveness. At the same time, team members could be from the same nation-state, but from very different socio-economic or cultural backgrounds, in which case they will bring different perspectives and give the team access to different knowledge and resource pools. Thus, we posit that the diversity of backgrounds of the team members, such as the institutional, economic, religious and cultural environments they come from leads to positive outcomes. 


\section{Hypothesis 3: Contextual diversity will have a positive effect on a) task outcomes and b) psychological outcomes.}

Because the mechanism by which diversity exerts a positive effect is different from that of the negative effects, these types of diversity affect different team effectiveness indicators differently. The negative effects manifest themselves at the interpersonal level, whereas the positive effects stem from contextual differences. At the personal level, diversity reduces attraction, comfort, and makes communication harder and thus has a negative effect, particularly on psychological satisfaction. At the contextual level, diversity allows team members to tap into different pools of knowledge, connections, and resources, which in turn increases the number of solutions the team can consider, which then improves decision making, problem solving, and performance.

A closer inspection of the positive-effect mechanisms proposed by writings from information processing theory (Simon, 1978) and the resource-based view of the firm (Barney, 1991) reveal that they primarily refer to the results of the team work, such as the quality of the output the team produces or the creativity or innovativeness of their ideas. This line of argument also aligns with Stahl and colleagues' (2010) argument that deep-level diversity, which fits within our contextual diversity concept, affects mainly team creativity and task performance. This hypothesis is based on the assumption that the variety of perspectives, knowledge, and resource pools leads to better decisions and solutions, even though the positive effects on personal satisfaction may be less pronounced. We expect that contextual diversity will have a positive effect on both facets of team effectiveness, but the relative effect on task outcomes will be stronger than on the psychological outcomes.

\section{Hypothesis 4: Contextual diversity will have a stronger positive effect on task outcomes than on psychological outcomes.}

\section{METHOD}

\subsection{Sample}

To test our hypotheses, we use data from a large multi-country collaborative project involving 5,728 students working in 804 GVTs across 132 universities. On average, each team had 7.1 members, with an average of 5.2 countries represented per team. The average age of our study participants was 23.9. The average work experience in the sample was over three years, $31 \%$ of participants were employed at the time of the study, and $5 \%$ reported owning their own business or holding managerial positions, thus "doubling up" as corporate employees with considerable work experience. Furthermore, $41 \%$ of the participants were MBA and EMBA students. Aware of concerns around student samples in business research (e.g., editorials by Bello, Leung, Radebaugh, Tung, \& Van Witteloostuijn, 2009; Wheeler, Shanine, Leon, \& Whitman, 2014), we considered the generalizability concerns. As our sample had a substantial age range with our oldest participant being 67 years old, we tested and found that age did not significantly correlate with any of the variables in our model. This suggests that the younger age of our study participants does not present a major threat to the generalizability.

We designed the project task and environment to resemble the corporate world as closely as possible. The project length was extensive, requiring 8-9 weeks of collaborative work. Completing the project required frequent communication and close collaboration. Further, students were randomly assigned to teams and the project involved the development 
of a solution to real-life business challenges. The task included market research, market entry plan development, and product design. Our instructors, many with rich business consulting experience, managed the project as if it was a regular business consulting project. Importantly, students felt pressure to perform. On average, the project accounted for $35 \%$ of the course grade. A failure on the project often meant a failure in the course, with all resulting potential negative effects on future career prospects. Given these conditions, the stakes and motivation were high and more resembled those associated with corporate project teams. This is in contrast to the typical small payment that researchers offer to students for participating in a study (e.g., Brockner, De Cremer, van den Bos, \& Chen, 2005; Gelfand \& Christakopoulou, 1999).

\subsection{Measures}

The goal of the study was to simultaneously test and compare the effects of many different indicators of diversity on team effectiveness. Accordingly, for personal diversity, we selected demographics (age, gender), differences in skills and attitudes more relevant to work in GVTs (communication and technical skills plus cultural intelligence), and perceived differences (aka "psychic distance”, c.f., O’Grady, Lane, 1996). For contextual diversity we focused on the main commonly accepted economic, political, cultural, and institutional characteristics of each participants' home country.

All variables used in the present study were derived from individual-level indicators aggregated to the team level. To eliminate the threat of common method bias (Podsakoff et al. 2003), the data are drawn from multiple sources. Specifically, task outcomes were measured by professors evaluating the outcome (report) for each team. Psychological outcomes were measured based on participant survey responses at the conclusion of the project. Contextual diversity was based on archival, publicly available data based on team members' country affiliation. Finally, personal diversity was measured based on survey responses at the beginning or during the project. Thus, all data were drawn from different sources or at different points in time, which should eliminate concerns about common method bias.

To capture team diversity, we used the standard deviation approach (Thomas, 1999). For each indicator, we calculated diversity by squaring every member's distance from the team's average and then taking a square root of the sum of squares. ${ }^{1}$

\subsubsection{Personal Diversity}

Seven personal diversity dimensions were captured in our dataset and included in the analysis: Age diversity was the standard deviation of the team members' ages. Gender diversity was operationalized as gender heterogeneity in the team. A perfectly gender-homogeneous team would be one with $100 \%$ male or female members, while a perfectly mixed team would be 50-50\% male-female. We calculated the index as 1.0 minus the absolute distance from 0.50 gender ratio. This way, the values would range from $0.50=$ perfectly homogeneous $(100 \%$ male or female) to $1.0=$ perfectly heterogeneous $(50-50 \%$ male-female $)$.

Each team member rated all other team members' English proficiency with an interrater reliability of 0.74. Working language skills diversity was measured as the standard deviation of English proficiency skills among the team members.

${ }^{1}$ An alternative method, the average team diversity method, calculates the absolute difference between all possible team member pairs and then taking an average. As a robustness check, we tried both computations. The two sets of indices were almost perfectly inter-correlated (0.97) and their correlations with external variables were almost identical. Therefore, we only report the results obtained using diversity indices calculated as standard deviations. 
Technical skills diversity was measured in the same manner. Team members evaluated their peers in terms of their technical abilities and knowledge to use advanced online communication and collaboration tools. The inter-rater reliability was 0.71 .

Personal value diversity was measured by assessing the values of each project participant (Dorfman \& Howell 1988). The instrument consisted of 28 items, measuring individual values pertaining to individualism, power distance, uncertainty avoidance, achievement orientation, and gender role attitudes. The internal consistency of the instrument ranged from 0.69 to 0.82 .

Cultural intelligence diversity was measuring using the BCIQ cultural intelligence instrument (Alon, Meyers, Boulanger, \& Taras, 2016). The internal reliability of the instrument ranged from 0.68 to 0.88. Perceived difference was measured by two items. At the start of the project, each team member was asked to indicate the degree of perceived differences between the countries represented on the team, and the perceived difficulty people from these countries would have working together. The two items correlated at the 0.85 level indicating a high internal consistency of this composite index. Importantly, perceived difference is fundamentally different from contextual diversity. Contextual diversity deals with objective differences of the contexts (e.g., national economic and political characteristics) that the team members come from. Perceived difference is a subjective personal perception of how similar or different the members of the team appear in terms of their cultural values and such.

For each of these scales, we calculated team diversity by averaging the standard deviations of the scores for each dimension. The resulting indices were similar to that offered by Kogut and Singh (1988), and basically indicated average absolute inter-member distance for each corresponding contract.

\subsubsection{Contextual Diversity}

Whereas all of the personal diversity measures were based on team member personal data, all of the contextual diversity measures were based on secondary data with each team member assigned a score based on his or her home country.

National variety was measured using Groves and Feyerherm's (2011) variety index. It is superior to simply counting the number of nationalities represented on the team as it takes into account the distribution of countries within the teams (i.e., even distribution or clear majority/minority). We used the student's nationality to operationalize this index, which appropriately captures the national variety regardless of the country of study.

Economic and social diversity were represented as standard deviations of a series of indicators that are typically used to describe economic and social institutions. Namely, we used gross domestic product per capita adjusted for purchasing power parity (PPP) (GDP/capita using PPP, World Bank data), Human Development Index (HDI, provided by the United Nations, 2015), and Gini Index (as reported in the CIA Factbook, 2011) as indicators of economic institutions; corruption level (Transparency International, 2015), civil freedom (Freedom House, 2015), the percent of parliament members who are female (InterParliamentary Union, 2013), religiosity levels (Gallup, 2015) and cultural diversity (calculated based on Hofstede's national cultural indices from Hofstede, 2001) as indicators of sociocultural institutions ${ }^{2}$. All of these were operationalized as a standard deviation of the national values generalized to the students on the team. National cultural value distance was

\footnotetext{
${ }^{2}$ For robustness, we also assessed the cultural diversity results using indicators from Schwartz (1992) and GLOBE data (House et al. 2004). Results were almost identical.
} 
operationalized as a standard deviation of the national cultural scores, as reported by Hofstede (2001) for the team members' country of origin.

Lastly, we measured both geographic and time-zone diversity, which where operationalized as average inter-member distances in kilometers and hours, respectively. The two are closely interrelated, but there are obvious differences. A GVT dispersed across Canada, Mexico and Argentina may face a different set of challenges than a GVT with members in Japan, France and the U.S.A.

\subsection{Dependent Variables}

\subsubsection{Task Outcomes}

Task outcomes were operationalized as the average expert rating of the team consulting report. At the end of the project, each team's output (consulting report) was evaluated by four to seven professors (supervisors). Each professor evaluated the report on eight dimensions, such as the economic feasibility and novelty of the idea, analysis quality and depth, formatting and visual appeal, and the overall quality of the report. The internal reliability was 0.85 and the inter-rater reliability was 0.72 to 0.91 depending on the evaluation dimension.

\subsubsection{Psychological Outcomes}

Psychological outcomes were measured as an average of the team members' satisfaction with the process and project overall, satisfaction with the quality of the report prepared by the team, and satisfaction with the team members expressed as the average of peer evaluations. The internal consistency of this index was 0.94. It is important to note that the selfevaluated report quality had a low correlation with the supervisor-assessed report quality $(\mathrm{r}=$ 0.11) indicating the former is indeed independent from the quality of the team output. Instead, member satisfaction is largely a psychological outcome of the project. The correlation between task outcomes and psychological outcomes was 0.24 indicating that the two are distinct dimensions of GVT effectiveness.

\subsection{Control Variables}

In addition to the focal inter-member diversity variables, as noted, we controlled for several basic team characteristics that are also expected to influence team effectiveness. This included team size, gender composition (percent male), along with average age, prior international experience, technical and working language skills, and cultural intelligence at the team level.

\section{RESULTS}

\subsection{Bivariate Correlation Analysis}

For our initial set of tests, we conducted correlation analyses. The complete correlation matrix (Table 1) suggests that not only the magnitude but also the direction of the effects vary dramatically. Evidently, team member diversity is not just "good" or "bad" for GVTs: different types of diversity have different effects on different dimensions of team effectiveness.

Table 2 provides a more focused overview of the bi-variate correlations between the various types of diversity and our key outcome variables. Hypothesis 1 predicted a negative effect between personal diversity and a) task outcomes and b) psychological outcomes, which is largely supported. Four of the seven personal diversity dimensions are negatively related to task outcomes and five out of seven are negatively related to psychological outcomes. None of the personal diversity dimensions have a significant positive effect. Further, the evidence 
suggests a stronger negative relationship with psychological outcomes than with task outcomes, which supports Hypothesis 2. Four of the seven negative correlations were significantly stronger for psychological outcomes than for task outcomes, and only gender diversity had a stronger negative relationship with task outcomes than with psychological outcomes. In other words, greater diversity among team members at the personal level, at least with respect to gender, working language, technical skills, cultural intelligence and perceived difference, tends to hurt team effectiveness, particularly the team dynamics aspect.

-Insert Tables 1 and 2 about here

However, not all personal differences affect team effectiveness. We found nonsignificant effects for age, which can perhaps be explained by the somewhat limited diversity offered by our student sample. More importantly, personal values diversity appeared to have a close-to-zero effect on either of the two aspects of GVT effectiveness.

In contrast, in support of Hypothesis 3, most of our contextual diversity measures had a positive effect on the task outcomes. Six (out of eleven) dimensions had a significant, positive relationship with task outcomes. Further, in support of Hypothesis 4, the positive effect of contextual diversity was limited to task outcomes. For psychological outcomes, only one dimension (civil freedom diversity) had a significant, positive relationship and one dimension (Gini diversity) had a significant negative relationship. Also, as expected, the positive effect was stronger for task outcomes and weaker for the psychological outcomes in about half of the cases.

Although there appears to be support for our hypotheses, it is very important to note that the effects of GVT diversity are not as strong and consistent as one might expect based on the attention the issue has received in the literature. In comparison, the basic team characteristics (controls) tend to have a stronger effect on team effectiveness than most of the team diversity measures. The next section reports the results of more sophisticated statistical tests of these relationships.

\subsection{Multivariate Regression Analysis}

To obtain more precise estimates of the partial effects of the different diversity dimensions, while controlling for basic team characteristics, we conducted a multivariate regression analysis. We present the regression results for psychological outcomes in Table 3 and for task outcomes in Table 4.

OLS regression assumes independence of predictors. Even moderate correlations among independent variables can results in misleading regression indices. As per Table 1, a number of our predictors correlated significantly with one another. Our tests for multicollinearity revealed only mild problems (VIF statistics in the 3.8 to 5.2 range). However, given our lengthy list of inter-correlated predictors, the variance explained $\left(\mathrm{R}^{2}\right)$ indices are of greater interest than the actual beta-coefficients. We used step-wise regression to analyze the cumulative effects of each block of predictors separately; that is the predictive power of personal diversity and contextual diversity as blocks. 
The regression results largely corroborated the findings from the initial bivariate correlations analysis. Several of the personal diversity indicators are negatively related to team effectiveness and the effects are stronger for psychological outcomes than for task outcomes. In contrast, several of the contextual diversity measures are positively related to task outcomes, more so than the psychological outcomes.

We also examined the amount of variance explained by the diversity constructs. As baseline, we first tested a model containing only the control variables (Models 1 and 7). Almost all of the basic team characteristics had a significant effect and together accounted for a substantial variance in team effectiveness, explaining $7 \%$ and $38 \%$ of the variance in task outcomes and psychological outcomes respectively.

We then added the personal diversity variables (Models 3 and 9). Taken together, they explained a statistically significant additional 2.5\% (task outcomes) to $2.7 \%$ (psychological outcomes) of the variance in team effectiveness. Of note, when tested without controls (Models 2 and 8) personal diversity explains $4.1 \%$ for task outcomes and a much larger $24.7 \%$ of variance in psychological outcomes. As we expected (Hypothesis 2), the link between personal diversity is much stronger to psychological outcomes than to task outcomes $\left(p<0.5\right.$ for $r^{2}$ difference test for Models 3 versus 9).

Next, we explored the effects of the contextual diversity block (Models 5 and 11). Controlling for basic team characteristics and qualifications, contextual diversity explains an additional $3.6 \%$ and $2.3 \%$ of variance in task outcomes and psychological outcomes, respectively. Again, when tested without controls (Models 4 and 10), contextual diversity explains $3.7 \%$ and $3.1 \%$ of variance in task outcomes and psychological outcomes. As per Hypothesis 4, contextual diversity explains more variance in task outcomes than in psychological outcomes, although the difference is marginally significant $\left(p<0.10\right.$ for $r^{2}$ difference test for Models 5 versus 11).

Looking at the combined predictive power (Models 6 and 12), diversity (personal and contextual taken together) explains an additional $7.7 \%$ and $6.0 \%$ of variance in task outcomes and psychological outcomes, respectively. Analyzed without the controls (not reported in Table 3 ), a combined diversity effect is $8.7 \%$ and $27.0 \%$ of variance explained in task outcomes and psychological outcomes. Thus, the explanatory power of the diversity variables is comparable to the explanatory power of the combined basic team characteristics and team member skills and qualifications.

\subsection{Post-Hoc Robustness Check}

As a robustness check, we repeated the analyses by creating personal and contextual diversity composite indices and used them in our analysis. Since the diversity variables in our dataset are measured on different scales, we first standardized the data with a mean of 0 and standard division of 1 . The personal and contextual diversity composite indices were computed as formative averages across the variables in each block (Diamantopoulos \& Siguaw, 2006). Table 5 provides correlations among the composite diversity indices and GVT outcomes.

Insert Table 5 about here

We revisited our hypotheses by analyzing the relationship between the diversity types and GVT performance measures using both bivariate correlations and multivariate regression analysis (Tables 5 and 6). The results further corroborate our theoretical model. Based on the bivariate correlations, personal diversity has a negative effect on both task outcomes and 
psychological outcomes (Hypothesis 1), and the effect is stronger $(\mathrm{p}<0.01)$ for psychological outcomes than for task outcomes (Hypothesis 2). The contextual diversity has a positive effect on both measures of GVT effectiveness (Hypothesis 3), and the effect is stronger for task outcomes (Hypothesis 4).

Multivariate regressions corroborate our results. Personal diversity has a significant negative effect on GVT effectiveness in every model specification (Hypothesis 1). Likewise, contextual diversity has a positive effect (Hypothesis 3) and much stronger and significant effect for task outcomes (Hypothesis 4), though the effect is significant only if the control variables are not used (Models 2 and 3).

Two of the eighteen constructs in our model were operationalized by the means of selfreport surveys. However, common method bias was not a serious threat because the data were aggregated from the individual to the team level and assessed at two different time points (Podsakoff et al. 2003). Further, the Harman's one factor test demonstrated that no single factor could explain the majority of variance. We also conducted a common latent factor test by subtracting the standardized weights from a model without a common latent factor from another model with an added common latent factor. As the highest value was .06, far below the threshold of .20 , this shows that common method bias was not a major threat to the validity of the results.

\section{DISCUSSION AND CONCLUSIONS}

The research on the effects of diversity in teams has been extensive. However, as noted before, the results have been conflicting, with some studies showing a positive effect, some negative, and others no effect at all. The present study attempts to clarify some of this ambiguity by simultaneously assessing and comparing the relative relationship among a multitude of diversity and effectiveness measures in a large single sample of GVTs working on a business consulting project. Further, we attempt to add to our theoretical understanding of GVT effectiveness by examining two distinct categories of diversity and two different aspects of GVT effectiveness.

The results of this study suggest that team diversity affects team effectiveness. However, they also show that the size and the direction of the effects vary across team diversity and effectiveness dimensions. Specifically, the data generally supported the notion that personal diversity tends to have a negative effect, and that the effect tends to be stronger for psychological outcomes than for task outcomes. In contrast, contextual diversity tends to have a positive effect, particularly on task outcomes. The findings have implications for both theory and practitioners.

\subsection{Theoretical Implications}

We would like to highlight three specific theoretical implications of this study. First, the measurement of performance is an elusive construct. Reviews of the general IB literature has found that many studies fail to consider the multi-faceted nature of performance (Hult et al., 2008). Similarly, inconsistent conceptualization and operationalization of performance make it difficult to synthesize findings across studies. In this study, we have explicitly considered two distinct aspects of performance. Furthermore, the correlation between task outcomes and psychological outcomes is rather weak, which suggests that the two facets will have unique antecedents. It also reinforces the importance for GVT research to carefully consider which facet(s) of performance the study is concerned with and to avoid conceptualizing and operationalizing GVT performance as a global latent construct. 
Second, the predictions for a negative relationship between personal diversity and GVT effectiveness were based on two related theories: similarity-attraction theory (Berscheid \& Walster, 1969; Byrne, 1971) and social identity theory (Tajfel, 1974). The basic premise of these theories suggest that people are attracted and drawn to other people who share similar characteristics and beliefs. This theoretical perspective received general support as most personal diversity measured were negatively related to GVT effectiveness. However, the findings were not uniform for both facets of performance as personal diversity has a stronger effect on psychological outcomes than on task outcomes. This provides new insights into these theories, illustrating that the effects of personal similarities may be more related to personal enjoyment and satisfaction, and less with actual objective performance.

Third, we make similar theoretical discoveries, but in the opposite direction, drawing on the resource-based view. It suggests that bundling more heterogeneous resources (i.e., greater team diversity) should be more valuable and enhance team success. In our GVT context, we find some support for this as the findings suggest that contextual diversity is largely positively related to task outcomes. However, although objective supervisor-rated performance may improve, it does not enhance participants' satisfaction and enjoyment of the project. The theoretical insights and particularly the differential effects as to what drives psychological outcomes compared with task outcomes has major managerial implications.

\subsection{Managerial Implications}

Some managers might argue that he or she should only be concerned about the objective performance of the GVT, and that employee satisfaction and enjoyment is beyond the manager's concerns. However, even though the correlation between psychological outcomes and task outcomes was rather modest in this study, an overall relationship between job satisfaction and job performance is well established. Thus, one would expect that, over time, low personal satisfaction would lead to lower performance and job switching, which suggests that managers would be best served being concerned about both task outcomes and psychological outcomes.

Our findings provide some guidance to help managers maximize both. The optimal team composition might be one where team members are similar in terms of their personal characteristics, such as age, gender, skills and perceptions, but as different as possible in terms of the characteristics of the societies they grew up in. This would allow to minimize interpersonal problems, while maximizing the team's tasks performance. Project scope may also influence whether managers should be more concerned about psychological outcomes or task outcomes. An emphasis on personal homogeneity may be more valuable on relatively routine projects with fewer demands for creative thinking, and where employee satisfaction and retention are important. In contrast, if the project requires complex problem solving and addressing difficult international business challenges, a team comprised of individuals of diverse backgrounds may achieve better results.

Our findings also reinforce that diversity is a very complex construct, and that managers should be reminded to not think about it as a single factor. When it comes to the issue of recruitment, selection, and team composition, it would be wrong to think about effectiveness of "diverse" versus "homogeneous" teams in general. There are many different types of diversity and many different types of team effectiveness and their relationships vary both in terms of direction and magnitude. Although managers may prefer simple actionable advice, our study reemphasizes that oversimplification may be counterproductive. At the very least, in a discussion about "team diversity," it is important to recognize that there are many types of diversities and to not lump them all in a single pile. 
It is also important to note that while the effects of the different types of team diversity on the different facets of team effectiveness are statistically significant and practically meaningful, team diversity still explains only a portion of variation in team effectiveness. In fact, some of the effects reported in this study are rather limited, particularly the effects of contextual diversity. We would like to warn managers that diversity is not a silver bullet that, once present in a team, will automatically lead great problem solving (or conversely to conflicts and interpersonal problems). It is a factor that clearly plays and role and must be taken into account when forming and managing teams, but it is only one of many factors that affect team effectives.

\subsection{Limitations and Direction for Future Research}

While the present study advances our understanding of the effects of diversity in GVTs in a number of important ways, it cannot address all relevant issues and much work still remains. For example, we evaluate a broad main effects model. Future research may want to expand our work by considering non-linear relationships and/or a range of moderators and mediators (Haas, 2010). For example, it is worth exploring the extent to which communication, effort, conflicts, and other team dynamic factors mediate the relationship between team diversity and effectiveness.

Second, we focused on team-level outcomes and averaged all constructs to the team level. However, it is likely that individual team members had unique experiences. Thus, future research may examine but individual-level outcomes, such as individual performance and commitment.

Third, our study was based on a student sample. Because the cultural diversity and geographic dispersion of our teams were real, the task involved a real consulting project for a corporate client, and the work design and incentive structure were similar to a corporate project environment, we do not see this as a major threat to the generalizability of our findings. However, there may be another issue related to our sampling procedures that we could not properly address in the present study. All participants were business students on their way to join the global business elite. There is a growing body of literature that suggests that the values and worldviews of the representatives of this global stratum may be relatively homogeneous (Berger, 1997; Taras, Steel, \& Kirkman, 2016). It is possible that the nature of our sample masked some of these effects. In fact, the rise of the "global elites" may explain the relatively weak effect of contextual diversity on team effectiveness observed in this study. As the characteristics of the social circles and economic and institutional environments of a business person in Brazil and a business person in in Germany are becoming more alike, the benefits offered by contextual diversity may be shrinking. If the global business elites are indeed becoming more alike, this important benefit of background diversity may be lost. It would be fruitful to explore this notion in more depth, building on what we found in this study. 


\section{REFERENCES}

Abbas, M., Raja, U., Darr, W., \& Bouckenooge, D. 2014. Combined effects of perceived politics and psychological capital on job satisfaction, turnover intentions, and performance. Journal of Management, 40(7): 1813-1830.

Alon, I., Boulanger, M., Meyers, J., \& Taras, V. 2016. The development and validation of the Business Cultural Intelligence Quotient. Cross Cultural \& Strategic Management, 23(1): 78-100.

Ang, S., Van Dyne, L., Koh, C., Ng, K.Y., Templer, K.J., Tay, C., \& Chandrasekar, N.A., 2007. Cultural intelligence: Its measurement and effects on cultural judgment and decision making, cultural adaptation and task performance. Management and Organization Review, 3(3): 335-371.

Baugh, S. G. \& Graen, G. B. 1997. Effects of team gender and racial composition on perceptions of team performance in cross-functional teams. Group \& Organization Management, 22(3): 366-83.

Bailey, W., \& Spicer, A. 2007. When does national identity matter? Convergence and divergence in international business ethics. Academy of Management Journal, 50(6), 1462-1480.

Beckerman, W. (1956). Distance and the pattern of intra-European trade. The Review of Economics and Statistics, 38(1), 31-40.

Bello, D., Leung, K., Radebaugh, L., Tung, R. L., \& Van Witteloostuijn, A. 2009. From the editors: Student samples in international business research. Journal of International Business Studies, 40(3), 361-364.

Berger, P. L. 1997. Four faces of global culture. The national interest, (49), 23-29.

Berscheid, E. \& Walster, E.H. 1969. Interpersonal Attraction. Massachusetts, AddisonWesley Publishing Company.

Bleijenbergh, I., Peters, P., Poutsma, E., \& Haas, H. 2010. How can we explain mixed effects of diversity on team performance? A review with emphasis on context. Equality, Diversity and Inclusion: An International Journal, 29(5), 458-490.

Brockner, J., De Cremer, D., van den Bos, K., \& Chen, Y.-R. (2005). The influence of interdependent self-construal on procedural fairness effects. Organizational Behavior and Human Decision Processes, 96(2), 155-167.

Byrne, D. 1971. The Attraction Paradigm. New York: Academic Press.

Caprar, D.V. 2011. Foreign locals: A cautionary tale on the culture of MNC employees. Journal of International Business Studies, 42(5): 608-628.

Cannella, A. A., Park, J. H., \& Lee, H. U. 2008. Top management team functional background diversity and firm performance: Examining the roles of team member colocation and environmental uncertainty. Academy of Management Journal, 51(4): 768-84.

Cantwell, J., Dunning, J. H., \& Lundan, S. M. 2010. An evolutionary approach to understanding international business activity: The co-evolution of MNEs and the institutional environment. Journal of International Business Studies, 41(3): 567-586.

Chang, S.-J., Van Witteloostuijn, A., \& Eden, L. 2010. From the editors: Common method variance in international business research. Journal of International Business Studies, 41(2), 178-184.

Chudoba, K., Wynn, E., Lu, M., \& Watson-Manheim, M. B. 2005. How virtual are we? Measuring virtuality in a global organization. Information Systems Journal, 15: 279306. 
Cox, T.H., Label, S., \& McLeod, P. 1991. Effects of ethnic group cultural differences on cooperative and competitive behavior on a group task. Academy of Management Journal, 34(4): 827-847.

De Cuyper, N., Castanheira, F., de White, H., \& Chambel, M.J. 2014. A multiple-group analysis of associations between emotional exhaustion and supervisor-rated individual performance: Temporary versus permanent call-center workers. Human Resource Management, 53(4): 623-633.

CIA (2011). Distribution of family income - Gini index, The World Factbook, accessed on November 24, 2015 at https://www.cia.gov/library/publications/the-worldfactbook/fields/2172.html

Diamantopoulos, A., \& Siguaw, J. A. 2006. Formative versus reflective indicators in organizational measure development: A comparison and empirical illustration. British Journal of Management, 17(4), 263-282.

DiStefano, J. J., \& Maznevski, M. L. 2000. Creating value with diverse teams in global management. Organizational Dynamics, 29(1), 45-63.

Dorfman, P., \& Howell, J. P. 1988. Dimensions of national culture and effective leadership patterns: Hofstede revisited. In R. N. Farmer \& E. G. McGoun (Eds.), Advances in International Comparative Management (pp. 172-150). London, UK: JAI Press.

Duckworth, H. 2008. How TRW automotive helps global virtual teams perform at the top of their game. Global Business and Organizational Excellence, 28(1): 6-16.

Earley, P. C. \& Mosakowski, E. 2000. Creating hybrid team cultures: An empirical test of transnational team functioning. Academy of Management Journal, 43(1): 26-50.

Eisenberg, J., \& Mattarelli, E. 2017. Building bridges in global virtual teams: the role of multicultural brokers in overcoming the negative effects of identity threats on knowledge sharing across subgroups. Journal of International Management, 23(4): 341-349.

Ely, R. J. 2004. A field study of group diversity, participation in diversity education programs, and performance. Journal of Organizational Behavior, 25(6): 755-80.

Freedom House (2015) Freedom in The World - Populists and Autocrats: The Dual Threat to Global Democracy by Freedom House, retrieved December 15, 2015 at https://freedomhouse.org/sites/default/files/FH_FIW_2017_Report_Final.pdf

Gallup Survey 2015. Religiosity Highest in World's Poorest Nations. Gallup. Retrieved December 15, 2015 at http://www.gallup.com/poll/1690/religion.aspx

Gelfand, M. J., \& Christakopoulou, S. (1999). Culture and negotiator cognition: Judgment accuracy and negotiation processes in individualistic and collectivistic cultures. Organizational Behavior \& Human Decision Processes, 79(3), 248-269.

Grant, R. M. 1996. Toward a knowledge-based theory of the firm. Strategic Management Journal, 17: 109-122.

Groves, K. S., \& Feyerherm, A. E. 2011. Leader cultural intelligence in context: Testing the moderating effects of team cultural diversity on leader and team performance. Group \& Organization Management, 36(5), 535-566.

Haas, H. 2010. How can we explain mixed effects of diversity on team performance? A review with emphasis on context. Equality, Diversity and Inclusion: An International Journal, 29(5): 458-490.

Hackman, J.R. 1987. The design of work teams. In J.W. Lorsch (Ed.), Handbook of organizational behavior, pp. 315-342. Englewood Cliffs, NJ: Prentice-Hall.

Hambrick, D. 2007. The field of management's devotion to theory: Too much of a good thing? Academy of Management Journal, 50(6): 1346-1352. 
Harrison, D. A. \& Klein, K. J. 2007. What's the difference? Diversity constructs as separation, variety, or disparity in organizations. Academy of Management Review, 32: 1199-228.

Harrison, D. A., Price, K. H., \& Bell, M. P. 1998. Beyond relational demography: Time and the effects of surface- and deep-level diversity on work group cohesion. The Academy of Management Journal, 41(1): 96-107.

Hertel, G., Geister, S., \& Kondradt, U. 2005. Managing virtual teams: A review of current empirical research. Human Resource Management Review, 15: 65-95.

Hofstede, G. 1980. Cultural Consequences: International Differences in Work Related Values. Beverly Hills: Sage Publications.

Hofstede, G. 2001. Culture's Consequences: Comparing Values, Behaviors, Institutions, and Organizations across Nations (2 ed.). London: Sage Publications.

Horwitz, S. B. \& Horwitz, I. B. 2007. The effects of team diversity on team outcomes: A meta-analytic review of team demography. Journal of Management, 33(6): 987-1015.

House, R. J., Hanges, P. J., Dorfman, P. W., \& Gupta, V. 2004. Culture, Leadership and Organizations: The GLOBE Study of 62 Nations. Thousand Oaks, CA: Sage.

Inter-Parliamentary Union (2013) Women in Parliaments: World Classification. Retrieved retrieved December 15, 2015 at http://www.ipu.org/wmn-e/classif.htm

Jackson, S. E. 1992. Team composition in organizational settings: Issues in managing an increasingly diverse workforce. In Worchel, S., W. Wood, \& J.A. Simpson, (Eds.), Group Process and Productivity. Newbury Park, MA: Sage.

Jackson, S. E., \& Joshi, A. 2004. Diversity in social context: A multi-attribute, multilevel analysis of team diversity and sales performance. Journal of Organizational Behavior, 25(6), 675-701.

Janis, I. L. 1982. Groupthink. Boston: Houghton Mifflin.

Jarvenpaa, S. L., \& Leidner, D. E. 1999. Communication and trust in global virtual teams. Organization Science, 10(6), 791-815.

Jiménez, A. Boehe, D.M. Taras, V., \& Caprar, D.V. 2017. Working across boundaries: Current and future perspectives on Global Virtual Teams. Journal of International Management, 23(4): 341-349.

Kamoche, K. 1997. Knowledge creation and learning in international HRM. International Journal of Human Resource Management, 8(3): 213-25.

Kirkman, B. L., Rosen, B., Tesluk, P. E., \& Gibson, C. B. 2004. The impact of team empowerment on virtual team performance: The moderating role of face-to-face interaction. Academy of Management Journal, 47: 175-92.

Kirkman, B. L. \& Shapiro, D. L. 2005. The impact of cultural value diversity on multicultural team performance. In Shapiro, Debra L., Mary Ann Von Glinov, \& Joseph L. C. Cheng, (Eds.), Managing Multinational Teams: Global Perspectives. Amsterdam: Elsevier.

Kogut, B. \& Singh, H. 1988. The effect of national culture on the choice of entry mode. Journal of International Business Studies, 19: 411-32.

Kozlowski, S. W. J. \& Bell, B. S. 2003. Work groups and teams in organizations. In Borman, W. C., D. R. Ilgen, \& R. J. Klimoski, (Eds.), Handbook of Psychology: Industrial and Organizational Psychology. New York: Wiley and Sons.

Kristof, A. L., Brown, K. G., Sims, H. P., \& Smith, K. A. 1995. The virtual team: A case study and inductive model. In Beyerlein, M. M., D. A. Johnson, \& S. T. Beyerlein, (Eds.), Advances in Interdisciplinary Studies of Work Teams: Knowledge Work in Teams. Greenwich, CT: JAI Press.

Lipnack, J. \& Stamps, J. 1997. Virtual teams: Reaching across space, time and organizations with technology: New York: John Wiley and Sons. 
Lisak, A., Erez, M., Sui, Y.\& Le, C. 2016. The positive role of global leaders in enhancing multicultural team innovation. Journal of International Business Studies, 47: 655-673

Magnusson, P., Schuster, A., \& Taras, V. (2014). A Process-Based Explanation of the Psychic Distance Paradox: Evidence from Global Virtual Teams. Management International Review, 54(3), 283-306.

Martins, L. L., Gilson, L. L., \& Maynard, M. T. 2004. Virtual teams: What do we know and where do we go from here? Journal of Management, 30(6): 805-835.

Maznevski, M. L. \& Chudoba, K. 2000. Bridging space over time: global virtual team dynamics and effectiveness. Organization Science, 11(5): 473-492.

McMahon, A. M. 2010. Does workplace diversity matter. Journal of Diversity Management, 5(1): 37-48.

Milliken, F. J., \& Martins, L. L. 1996. Searching for common threads: Understanding the multiple effects of diversity in organizational groups. Academy of Management Review, 21(2), 402-433.

Montoya-Weiss, M., Massey, A., \& Song, M. 2001. Getting it together: Temporal coordination and conflict management in global virtual teams. Academy of Management Journal, 44: 1251-1262.

Muchinsky, P. M. (1996). The correction for attenuation. Educational and Psychological Measurement, 56(1), 63-75.

Muethel, M. \& Hoegl, M. 2010. Cultural and societal influences on shared leadership in globally dispersed teams. Journal of International Management, 16(3): 234-46.

Ng, E. S., \& Tung, R. L. 1998. Ethno-cultural diversity and organizational effectiveness: A field study. International Journal of Human Resource Management, 9(6), 980-995.

Nemiro, J. 2002. The creative process in virtual teams. Creativity Research Journal, 14: 6983.

Nielsen, S. 2010. Top management team diversity: A review of theories and methodologies. International Journal of Management Reviews, 12(2): 301-316.

O'Grady, S. \& Lane, H.W. 1996. The psychic distance paradox. Journal of International Business Studies, 27(2): 309-333.

O’Reilly, C. A., Williams, K. Y., \& Barsade, S. 1998. Group demography and innovation: Does diversity help? In E. Mannix \& M. Neale (Eds), Research in the Management of Groups and Teams, Vol. 1: 183-207. Greenwich, CT: JAI Press.

Oyserman, D., Coon, H. M., \& Kemmelmeier, M. 2002. Rethinking individualism and collectivism: Evaluation of theoretical assumptions and meta-analysis. Psychological Bulletin, 128, 3-72.

Paletz, S. B. F., Pavisic, I., Miron-Spektor, E., \& Lin, C.-C. 2018. Diversity in creative teams: Reaching across cultures and disciplines. In L. Y.-Y. Kwan, S. Liou, \& A. K.-Y. Leung (Eds.), Handbook of Culture and Creativity: Basic Processes and Applied Innovations. Oxford University Press.

Podsakoff, P. M., MacKenzie, S. B., Lee, J.-Y., \& Podsakoff, N. P. 2003. Common method biases in behavioral research: a critical review of the literature and recommended remedies. Journal of Applied Psychology, 88(5), 879-897.

Roberson, Q., Holmes, O., \& Perry, J. 2017. Transforming Research on Diversity and Firm Performance: A Dynamic Capabilities Perspective. Academy of Management Annals, 11(1): 189-216.

$\mathrm{RW}^{3}$ CultureWizard. 2016. Trends in global virtual teams. Retrieved from https://www.rw3.com/virtual-teams-survey-0

Schulz, M. 2001. The uncertain relevance of newness: Organizational learning and knowledge flows. Academy of Management Journal: 661-81. 
Schwartz, S. H. 1992. Universals in the content and structure of values: Theoretical advances and empirical tests in 20 countries. Advances in Experimental Social Psychology, 25: $1-65$.

Simon, H. A. 1978. Information-processing theory of human problem solving. Handbook of Learning and Cognitive Processes 5: 271-295.

Shaw, J. B. \& Barrett-Power, E. 1998. The effects of diversity on small work group processes and performance. Human Relations, 51(10): 1307-25.

Shenkar, O., Luo, Y., \& Yeheskel, O. 2008. From "distance" to "friction": Substituting metaphors and redirecting intercultural research. Academy of Management Review, 33(4), 905-923.

Shirts, R. G. 1974. Bafa-Bafa by Simulation Training Systems, http://www.simulationtrainingsystems.com/corporate/products/bafa-bafa/

Siemsen, E., Roth, A., \& Oliveira, P. 2010. Common method bias in regression models with linear, quadratic, and interaction effects. Organizational Research Methods, 13(3), 456-476.

Spearman, C. 1904. The proof and measurement of association between two things. American Journal of Psychology, 15, 72-101.

Stahl, G. K., Maznevski, M. L., Voigt, A., \& Jonsen, K. 2010. Unraveling the effects of cultural diversity in teams: A meta-analysis of research on multicultural work groups. Journal of International Business Studies, 41(4): 690-709.

Stahl, G. K., \& Tung, R. L. 2014. Towards a more balanced treatment of culture in international business studies: The need for positive cross-cultural scholarship. Journal of International Business Studies, 46(4), 391-414.

Stahl, G. K., Tung, R. L., Kostova, T., \& Zellmer-Bruhn, M. 2016. Widening the lens: Rethinking distance, diversity, and foreignness in international business research through positive organizational scholarship. Journal of International Business Studies, 47(6)621-630.

Tajfel, H. 1974. Social identity and intergroup behaviour. Social Science Information, 13(2): 65-93.

Taras, V., Steel, P., \& Kirkman, B. L. 2016. Does country equate with culture? Beyond geography in the search for cultural entities. Management International Review. 54(4): 455-472.

Thomas, D. C. 1999. Cultural diversity and work group effectiveness: An Experimental study. Journal of Cross-Cultural Psychology, 30(2): 242-263.

Thomas, D. C., Ravlin, E. C., \& Wallace, A. W. 1996. Effect of cultural diversity in work groups. In Erez, M. \& S. B. Bacharach, (Eds.), Research in the sociology of organizations. Greenwich, CT: JAI Press.

Tihanyi, L., Griffin, D. A., \& Russell, C. J. 2005. The effect of cultural distance on entry mode choice, international diversification, and MNE performance: A meta-analysis. Journal of International Business Studies, 36(3): 270-283.

Townsend, A. M., DeMarie, S. M., \& Hendrickson, A. R. 1998. Virtual teams: Technology and the workplace of the future. Academy of Management Executive, 12: 17-29.

Transparency International 2015. "Corruption Perceptions Index". Transparency International. Retrieved 14 December 2015, at http://www.transparency.org/research/cpi/overview

United Nations, (2015). Human Development Report 2015 - "Sustaining Human Progress: Reducing Vulnerabilities and Building Resilience"", Human Development Report Office of United Nations Development Programme. Retrieved 14 December 2015 at http://hdr.undp.org/sites/default/files/hdr_2015_statistical_annex.pdf 
Van Knippenberg, D., De Dreu, C. K., \& Homan, A. C. 2004. Work group diversity and group performance: an integrative model and research agenda. Journal of Applied Psychology, 89(6), 1008-1022.

Vahtera, P., Buckley, P. J., Aliyev, M., Clegg, J., \& Cross, A. R. 2017. Influence of social identity on negative perceptions in global virtual teams. Journal of International Management, 23(4): 341-349.

Watson, W. E., Kumar, K., \& Michaelsen, L. K. 1993. Cultural diversity's impact on interaction process and performance: Comparing homogeneous and diverse task groups. Academy of Management Journal, 36(3): 590-602.

Webber, S. S., \& Donahue, L. M. 2001. Impact of highly and less job-related diversity on work group cohesion and performance: a meta-analysis. Journal of Management, 27(2), 141-162

Wernerfelt, B. 1984. A resource-based view of the firm. Strategic Management Journal, 5(2): 171-180.

Wheeler, A. R., Shanine, K. K., Leon, M. R., \& Whitman, M. V. (2014). Student-recruited samples in organizational research: A review, analysis, and guidelines for future research. Journal of Occupational and Organizational Psychology, 87(1), 1-26.

Williams, K. Y. \& O'Reilly, C. A. 1998. Demography and diversity in organizations: A review of 40 years of research. Research in Organizational Behavior, 20(77): 140.

Windsor, D. 2001. International virtual teams: Opportunities and issues. Virtual Teams, 8: 139.

World Bank (2016). "GDP per capita, PPP (current international \$)", World Development Indicators database, World Bank. Database updated on 16 December 2016. Accessed on 23 December 2016 at http://databank.worldbank.org/data/download/GDP_PPP.pdf

Zakaria, N. 2009. Using computer mediated communication as a tool to facilitate intercultural collaboration of global virtual teams, in: Encyclopedia of Multimedia Technology and Networking. Information Science Reference, New York, pp. 11151123.

Zakaria, N. 2017. Emergent patterns of switching behaviors and intercultural communication styles of global virtual teams during distributed decision making. Journal of International Management, 23(4): 341-349. 
7. Tables and Figures

Figure 1. The Effects of Different Types of Diversity on Team Effectiveness

\section{Team Effectiveness}

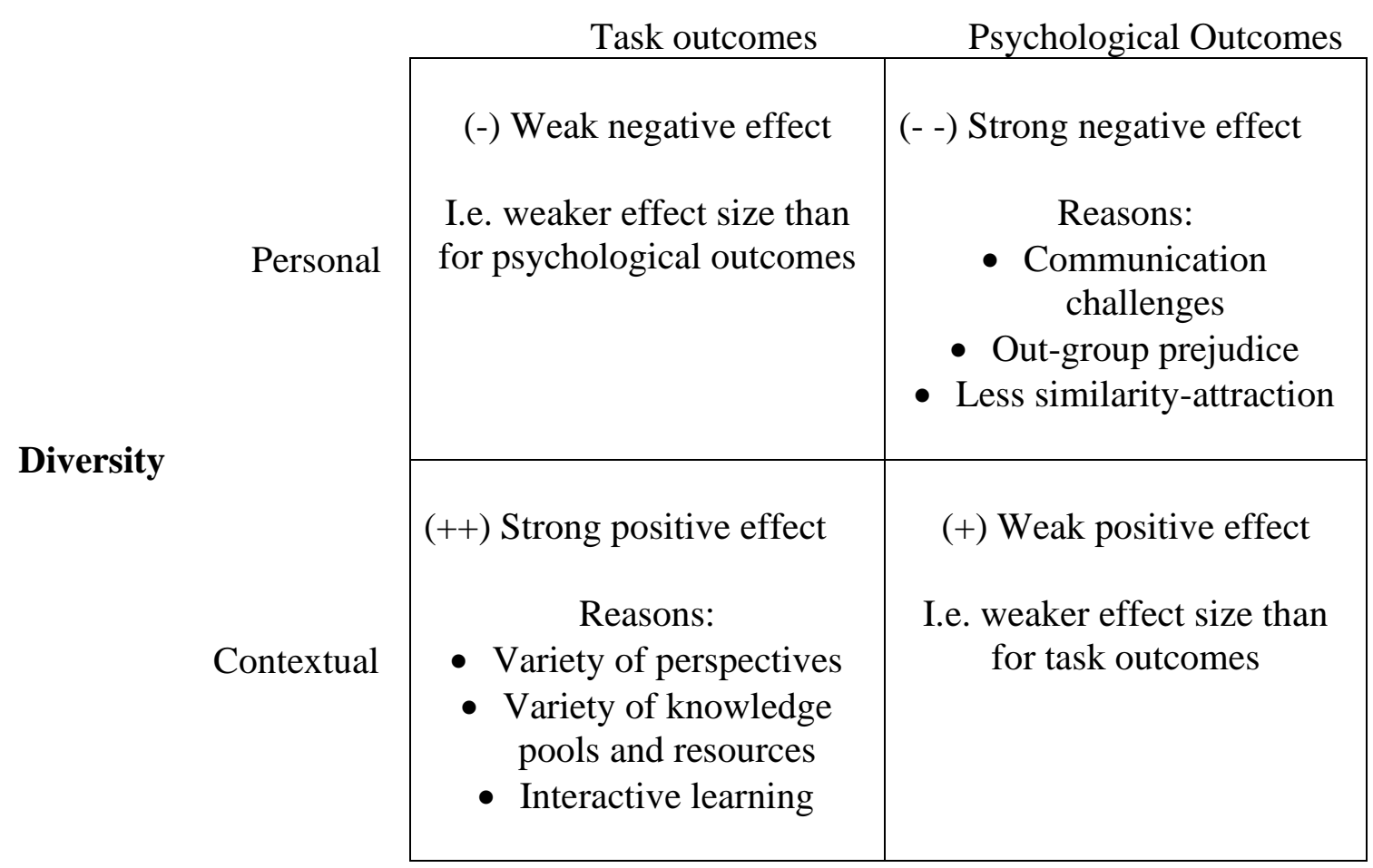

(- -) and (-) indicate negative effects where (- -) denotes a relatively stronger negative effect than $(-)$;

$(++)$ and $(+)$ indicate positive effects where $(++)$ denotes a relatively stronger positive effect than (-) 
Table 1. Complete Correlation Matrix

\begin{tabular}{|c|c|c|c|c|c|c|c|c|c|c|c|c|c|c|c|c|}
\hline & 1 & 2 & 3 & 4 & 5 & 6 & 7 & 8 & 9 & 10 & 11 & 12 & 13 & 14 & 15 & 16 \\
\hline \multicolumn{17}{|l|}{ Team effectiveness } \\
\hline 1. Task outcomes & $(0.85)$ & & & & & & & & & & & & & & & \\
\hline 2. Psychological outcomes & 0.24 & $(0.94)$ & & & & & & & & & & & & & & \\
\hline \multicolumn{17}{|l|}{ Controls } \\
\hline 3. Team size & -0.09 & 0.01 & $(\mathrm{~N} / \mathrm{A})$ & & & & & & & & & & & & & \\
\hline 4. Percent male & -0.14 & -0.10 & 0.10 & (N/A) & & & & & & & & & & & & \\
\hline 5. Avg. team age & 0.06 & 0.05 & 0.14 & 0.15 & $(\mathrm{~N} / \mathrm{A})$ & & & & & & & & & & & \\
\hline 6. Avg. international experience & 0.10 & -0.03 & -0.47 & -0.07 & -0.07 & $(\mathrm{~N} / \mathrm{A})$ & & & & & & & & & & \\
\hline 7. Avg. technical skills & 0.19 & 0.59 & -0.11 & -0.10 & -0.07 & -0.04 & $\left(0.71^{\prime}\right)$ & & & & & & & & & \\
\hline 8. Avg. working language skills & 0.15 & 0.50 & -0.17 & -0.08 & -0.07 & -0.03 & 0.81 & $\left(0.74^{\prime}\right)$ & & & & & & & & \\
\hline 9 Avg. cultural intelligence & 0.10 & 0.20 & -0.27 & -0.05 & -0.10 & 0.14 & 0.19 & 0.15 & $(0.78)$ & & & & & & & \\
\hline \multicolumn{17}{|l|}{ Personal diversity } \\
\hline 10. Age $^{\mathrm{s}}$ & 0.01 & 0.02 & 0.10 & 0.10 & 0.83 & -0.09 & -0.07 & -0.07 & -0.08 & $(\mathrm{~N} / \mathrm{A})$ & & & & & & \\
\hline 11. Gender ${ }^{s}$ & -0.11 & -0.06 & 0.14 & 0.41 & 0.08 & -0.07 & -0.08 & -0.08 & -0.05 & 0.06 & $(\mathrm{~N} / \mathrm{A})$ & & & & & \\
\hline 12. Working language skills ${ }^{\mathrm{s}}$ & -0.12 & -0.34 & 0.08 & 0.07 & 0.01 & 0.09 & -0.60 & -0.70 & -0.13 & 0.05 & 0.10 & $\left(0.74^{\prime}\right)$ & & & & \\
\hline 13. Technical skills ${ }^{\mathrm{d}}$ & -0.11 & -0.35 & 0.09 & 0.07 & 0.04 & 0.10 & -0.67 & -0.55 & -0.16 & 0.06 & 0.06 & 0.79 & $\left(0.71^{\prime}\right)$ & & & \\
\hline 14. Personal values ${ }^{\mathrm{d}}$ & -0.01 & 0.00 & 0.05 & -0.03 & 0.02 & 0.07 & -0.04 & 0.03 & -0.02 & 0.00 & 0.04 & 0.00 & 0.04 & $(0.86)$ & & \\
\hline 15. Cultural intelligence ${ }^{d}$ & -0.02 & -0.09 & -0.05 & 0.01 & -0.11 & -0.06 & -0.05 & -0.06 & 0.11 & -0.07 & -0.02 & 0.05 & 0.06 & 0.04 & $(0.78)$ & \\
\hline 16. Perceived difference ${ }^{\mathrm{d}}$ & -0.17 & -0.41 & 0.03 & -0.04 & -0.06 & 0.01 & -0.35 & -0.34 & -0.17 & -0.02 & -0.02 & 0.23 & 0.23 & 0.06 & 0.04 & $(0.85)$ \\
\hline \multicolumn{17}{|l|}{ Contextual diversity } \\
\hline 17. National variety $\mathrm{s}$ & 0.09 & 0.02 & 0.02 & -0.10 & 0.03 & 0.15 & 0.02 & 0.00 & 0.03 & 0.01 & 0.03 & -0.06 & -0.05 & 0.05 & -0.04 & 0.06 \\
\hline 18. GDP/capita PPP & 0.01 & 0.04 & -0.26 & -0.08 & -0.07 & -0.03 & 0.08 & 0.18 & -0.03 & -0.05 & -0.06 & 0.01 & 0.02 & 0.04 & 0.08 & 0.08 \\
\hline 19. HDI & -0.04 & 0.00 & 0.10 & -0.05 & 0.33 & 0.02 & -0.17 & -0.14 & -0.18 & 0.26 & -0.03 & 0.11 & 0.16 & 0.11 & -0.13 & 0.24 \\
\hline 20. GINI & 0.02 & -0.08 & -0.09 & 0.02 & -0.14 & 0.13 & -0.03 & -0.06 & 0.07 & -0.06 & 0.05 & 0.07 & -0.01 & -0.05 & 0.00 & -0.03 \\
\hline 21. Corruption & 0.06 & 0.03 & -0.12 & -0.05 & 0.02 & 0.02 & 0.05 & 0.11 & -0.14 & 0.04 & -0.03 & 0.04 & 0.05 & 0.09 & -0.05 & 0.06 \\
\hline 22. Civil freedom & 0.01 & 0.09 & -0.10 & -0.18 & -0.16 & 0.08 & 0.07 & 0.06 & 0.05 & -0.15 & -0.08 & -0.09 & -0.07 & 0.04 & 0.04 & 0.08 \\
\hline 23. Percent women in parliament & 0.10 & 0.03 & 0.26 & 0.02 & 0.11 & -0.17 & 0.02 & -0.04 & -0.13 & 0.09 & 0.03 & -0.02 & -0.06 & -0.01 & -0.08 & -0.04 \\
\hline 24. Religiosity & 0.08 & -0.05 & 0.18 & -0.09 & 0.09 & 0.06 & -0.10 & -0.13 & -0.11 & 0.08 & -0.08 & 0.02 & 0.05 & 0.08 & -0.09 & 0.17 \\
\hline 25. National cultural value distance & 0.09 & 0.03 & -0.17 & -0.03 & -0.07 & 0.10 & 0.09 & 0.10 & 0.08 & -0.09 & -0.03 & -0.02 & -0.02 & -0.10 & 0.06 & -0.03 \\
\hline 26. Geographic dispersion & -0.02 & -0.02 & -0.19 & 0.01 & -0.23 & 0.18 & -0.01 & -0.02 & 0.18 & -0.19 & -0.03 & -0.02 & -0.05 & -0.06 & 0.13 & 0.16 \\
\hline 27. Time-zone dispersion (hours) & 0.05 & 0.03 & -0.10 & -0.06 & -0.24 & 0.02 & 0.04 & 0.02 & 0.05 & -0.17 & -0.09 & -0.03 & -0.05 & 0.00 & 0.07 & 0.12 \\
\hline
\end{tabular}


Table 1. Complete Correlation Matrix (cont'd)

\begin{tabular}{|c|c|c|c|c|c|c|c|c|c|c|}
\hline & 17 & 18 & 19 & 20 & 21 & 22 & 23 & 24 & 25 & 26 \\
\hline \multicolumn{11}{|l|}{ Contextual diversity } \\
\hline 17. National variety ${ }^{s}$ & (N/A) & & & & & & & & & \\
\hline 18. GDP/capita PPP & 0.17 & $(\mathrm{~N} / \mathrm{A})$ & & & & & & & & \\
\hline 19. HDI & 0.18 & 0.23 & (N/A) & & & & & & & \\
\hline 20. GINI & 0.15 & -0.17 & -0.30 & $(\mathrm{~N} / \mathrm{A})$ & & & & & & \\
\hline 21. Corruption & 0.16 & 0.69 & 0.35 & 0.00 & (N/A) & & & & & \\
\hline 22. Civil freedom & 0.17 & 0.13 & 0.11 & -0.19 & 0.23 & (N/A) & & & & \\
\hline 23. Percent women in parliament & 0.11 & -0.14 & 0.05 & 0.33 & 0.22 & -0.08 & (N/A) & & & \\
\hline 24. Religiosity & 0.20 & -0.15 & 0.37 & -0.09 & 0.04 & 0.14 & 0.21 & (N/A) & & \\
\hline 25. National cultural values & 0.24 & 0.47 & -0.14 & 0.12 & 0.34 & 0.09 & 0.08 & 0.08 & $(\mathrm{~N} / \mathrm{A})$ & \\
\hline 26. Geographic dispersion & 0.33 & 0.19 & -0.03 & 0.12 & 0.02 & 0.10 & -0.06 & 0.04 & 0.25 & $(\mathrm{~N} / \mathrm{A})$ \\
\hline 27. Time-zone dispersion (hours) & 0.29 & 0.24 & 0.02 & -0.01 & 0.15 & 0.14 & -0.03 & 0.16 & 0.26 & 0.77 \\
\hline
\end{tabular}

$\mathrm{N}=804$, correlations over 0.06 are significant at $\mathrm{p}<0.05$, correlations over 0.08 are significant at $\mathrm{p}<0.01$

Internal reliabilities in parentheses, (N/A) indicates presumed perfect measurement reliability or measured with a single direct question and Cronbach's alpha non-applicable

' Indicates inter-rater reliability, rather than internal reliability, obtained based on single-item peer-evaluations rather than multi-item self-report 
Table 2. Comparison of Bi-Variate Diversity Effects by the GVT Effectiveness Dimensions

\section{Team Effectiveness}

Task outcomes

Psychological outcomes

\section{Controls}

Team size

Percent male

Avg. team age

Avg. prior international experience

Avg. technical skills

Avg. working language skills

Avg. cultural intelligence

Personal Diversity

Age $^{\mathrm{s}}$

Gender ${ }^{\text {s }}$

Working language skills $\mathrm{s}$

Technical skills ${ }^{\mathrm{d}}$

Personal values ${ }^{\mathrm{d}}$

Cultural intelligence ${ }^{\mathrm{d}}$

Perceived differences ${ }^{\mathrm{d}}$

\section{Contextual Diversity}

National variety ${ }^{s}$

GDP/capita, PPP

HDI

Gini

Corruption

Civil freedom

Percent women in parliament

Religiosity

National cultural values diversity,

Hofstede

Geographic dispersion

Time zone dispersion

$* \mathrm{p}<0.05 ; * * \mathrm{p}<0.01$

$\mathrm{N}=804$
Task outcomes Psychological

Outcomes

Correlation

Difference

Significance

$0.240 * *$

$-0.086^{* *} \quad 0.010$

$*$

$-0.140^{* *} \quad-0.104 * *$

$0.061 * * \quad 0.050$

$0.097 * * \quad-0.030$

$0.193 * * \quad 0.593 * *$

$* *$

$0.151 * * \quad 0.503 * *$

$0.103 * *$

$0.196^{* *}$

**

$* *$

$* *$

$0.012 \quad 0.021$

$-0.113 * * \quad-0.060 *$

$-0.116^{* *} \quad-0.337 * *$

$-0.106^{* *} \quad-0.352^{* *}$

0.002

$-0.013$

$-0.086^{* *}$

$-0.020$

$-0.406^{* *}$

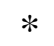

$* *$

$* *$

$-0.170^{* *}$

0.024

0.037

0.014

0.003

0.038

$-0.084 * *$

$* *$

0.021

$0.060 * *$

0.031

0.012

$0.091 * *$

$*$

$0.104^{* *} \quad 0.028$

$0.079 * * \quad-0.053$

$0.087 * *$

0.027

$-0.019$

$-0.021$

$0.050^{*}$

0.032 
Table 3. Multivariate Regression Results on Psychological Outcomes

\begin{tabular}{|c|c|c|c|c|c|c|}
\hline & Control & Personal & $\begin{array}{l}\text { Personal } \\
+ \text { Control }\end{array}$ & Contextual & $\begin{array}{l}\text { Contextual } \\
+ \text { Control }\end{array}$ & Full \\
\hline & (1) & $(2)$ & $(3)$ & (4) & (5) & $(6)$ \\
\hline Constant & $-0.031 * *$ & $5.487 * *$ & $1.118 * *$ & -.125 & -0.490 & $1.119 * *$ \\
\hline Team size & $0.060 * *$ & & $0.060 * *$ & & $0.068 * *$ & $0.059 * *$ \\
\hline Percent male & $-0.122 * *$ & & $-0.134 * *$ & & -0.073 & -0.097 \\
\hline Avg. team age & $0.020 * *$ & & $0.017 * *$ & & $0.013 * *$ & 0.006 \\
\hline Avg. intern 'l experience & 0.011 & & 0.012 & & $0.016 * *$ & 0.016 \\
\hline Avg. technical skills & $0.493 * *$ & & $0.423 * *$ & & $0.497 * *$ & $0.432 * *$ \\
\hline Avg. language skills & $0.131 * *$ & & $0.118^{*}$ & & $0.124 * *$ & 0.113 \\
\hline $\begin{array}{l}\text { Avg. cultural intelligence } \\
\text { Personal Diversity }\end{array}$ & $0.145^{* *}$ & & $0.128 * *$ & & $0.182 * *$ & $0.151 * *$ \\
\hline $\operatorname{Age}^{\mathrm{s}}$ & & 0.003 & -0.004 & & & -0.002 \\
\hline Gender $^{\mathrm{s}}$ & & -0.040 & 0.003 & & & -0.003 \\
\hline Working language skillss & & $-0.177 * *$ & 0.024 & & & 0.017 \\
\hline Technical skills d & & $-0.216^{* *}$ & 0.078 & & & 0.068 \\
\hline Personal values $^{\mathrm{d}}$ & & 0.122 & 0.083 & & & 0.042 \\
\hline Cultural intelligence $^{\mathrm{d}}$ & & $-0.206 * *$ & $-0.181 * *$ & & & $-0.144 * *$ \\
\hline $\begin{array}{l}\text { Perceived differences }{ }^{\mathrm{d}} \\
\text { Contextual Diversity }\end{array}$ & & $-0.350 * *$ & $-0.224 * *$ & & & $-0.276^{* *}$ \\
\hline National variety ${ }^{\mathrm{s}}$ & & & & 0.251 & 0.426 & 0.201 \\
\hline GDP/capita PPP & & & & 0.000 & 0.000 & 0.000 \\
\hline HDI & & & & -0.126 & $-1.029 * *$ & $-1.544 * *$ \\
\hline GINI & & & & $-0.014^{* *}$ & -0.003 & -0.004 \\
\hline Corruption & & & & -0.036 & -0.063 & $-0.079 * *$ \\
\hline Civil freedom & & & & $0.085^{* *}$ & $0.057 * *$ & $0.066 * *$ \\
\hline $\begin{array}{l}\text { Percent women in } \\
\text { parliament }\end{array}$ & & & & $0.014 * *$ & $0.007 *$ & $0.009 * *$ \\
\hline Religiosity & & & & $-0.007 * *$ & -0.005 & $-0.005^{* *}$ \\
\hline Cultural values & & & & 0.006 & -0.001 & 0.000 \\
\hline Geographic dispersion & & & & $0.024 * *$ & $0.000 * *$ & 0.003 \\
\hline Time-zone dispersion (hrs) & & & & $0.031 * *$ & $0.031 * *$ & 0.020 \\
\hline $\mathrm{R}^{2}$ & $0.383 * *$ & $0.247 * *$ & $0.410 * *$ & $0.031 * *$ & $0.406 * *$ & $0.443 * *$ \\
\hline $\begin{array}{l}\Delta \mathrm{R}^{2} \text { (compared to Control } \\
\text { model) }\end{array}$ & & $-0.136^{* *}$ & $0.027 * *$ & $-0.352 * *$ & $0.023 * *$ & $0.060 * *$ \\
\hline
\end{tabular}


Table 4. Multivariate Regression Results on Task outcomes

\begin{tabular}{|c|c|c|c|c|c|c|}
\hline & Control & Personal & $\begin{array}{l}\text { Personal } \\
+ \text { Control }\end{array}$ & Contextual & $\begin{array}{l}\text { Contextual } \\
+ \text { Control } \\
\end{array}$ & Full \\
\hline & $(7)$ & $(8)$ & $(9)$ & $(10)$ & $(11)$ & $(12)$ \\
\hline Constant & $2.090 * *$ & 6.407 & $2.386^{*}$ & $2.765 * *$ & -0.093 & 0.391 \\
\hline Team size & -0.014 & & 0.031 & & $-0.009 * *$ & 0.062 \\
\hline Percent male & $-0.428 * *$ & & $-0.441 * *$ & & $-0.454 * *$ & $-0.529 * *$ \\
\hline Avg. team age & $0.042 * *$ & & $0.081 * *$ & & $0.040 * *$ & $0.088 * *$ \\
\hline Avg. intern 'l experience & $0.035 * *$ & & -0.037 & & $0.052 * *$ & -0.013 \\
\hline Avg. technical skills & $0.386 * *$ & & $0.554 * *$ & & $0.365 * *$ & $0.503 * *$ \\
\hline Avg. language skills & -0.014 & & -0.199 & & -0.090 & -0.232 \\
\hline Avg. cultural intelligence & $0.133 *$ & & 0.044 & & $0.226 * *$ & $0.157 * *$ \\
\hline \multicolumn{7}{|l|}{ Personal Diversity } \\
\hline $\operatorname{Age}^{\mathrm{s}}$ & & 0.018 & -0.036 & & & $-0.036^{*}$ \\
\hline Gender ${ }^{\mathrm{s}}$ & & $-0.414 * *$ & $-0.267 * *$ & & & -0.132 \\
\hline Working language skills s & & -0.111 & -0.107 & & & -0.109 \\
\hline Technical skills & & -0.013 & $0.379 * *$ & & & $0.318 * *$ \\
\hline Personal values ${ }^{\mathrm{d}}$ & & -0.076 & -0.068 & & & -0.136 \\
\hline Cultural intelligence $^{\mathrm{d}}$ & & -0.044 & -0.036 & & & 0.042 \\
\hline Perceived differences ${ }^{\mathrm{d}}$ & & $-0.357 * *$ & $-0.282 * *$ & & & $-0.187 * *$ \\
\hline \multicolumn{7}{|l|}{ Contextual Diversity } \\
\hline National variety ${ }^{s}$ & & & & $2.102 * *$ & 0.376 & $1.164 *$ \\
\hline GDP/capita PPP & & & & 0.000 & 0.000 & 0.000 \\
\hline HDI & & & & $1.969 * *$ & $1.851 * *$ & $2.734 * *$ \\
\hline GINI & & & & -0.013 & $-0.018^{*}$ & -0.014 \\
\hline Corruption & & & & 0.089 & $0.136^{*}$ & 0.055 \\
\hline Civil freedom & & & & -0.066 & $-0.164 * *$ & -0.109 \\
\hline $\begin{array}{l}\text { Percent women in } \\
\text { parliament }\end{array}$ & & & & $0.024 * *$ & $0.023 * *$ & $0.029 * *$ \\
\hline Religiosity & & & & $0.009 * *$ & $0.007 *$ & $0.013 * *$ \\
\hline Cultural values & & & & 0.010 & 0.007 & 0.005 \\
\hline Geographic dispersion & & & & $0.054 * *$ & $0.065 * *$ & $-0.086^{* *}$ \\
\hline Time-zone dispersion (hrs) & & & & $0.045 *$ & $0.070 * *$ & $0.082 * *$ \\
\hline $\mathrm{R}^{2}$ & $0.071 * *$ & $0.041 * *$ & $0.096 * *$ & $0.037 * *$ & $0.107 * *$ & $0.148 * *$ \\
\hline $\begin{array}{l}\Delta \mathrm{R}^{2} \text { (compared to Control } \\
\text { model) }\end{array}$ & & $-0.030 * *$ & $0.025 * *$ & $-0.034 * *$ & $0.036 * *$ & $0.077 * *$ \\
\hline
\end{tabular}


Table 5. Correlations, Personal and Contextual Diversity Blocks

\begin{tabular}{lcccccc}
\hline & 1 & & & 3 & 4 & 5 \\
\hline 1. Task outcomes & 1.00 & 0.28 & -0.28 & -1.00 & 0.14 & 0.12 \\
2. Psychological outcomes & 0.25 & 1.00 & 0.64 & -0.61 & 0.01 & 0.03 \\
3. Personal diversity block, all 7 variables & -0.16 & -0.38 & 1.00 & 1.00 & 0.02 & -0.04 \\
4. Personal diversity block, select 5 variables & -0.18 & -0.42 & 0.91 & 1.00 & 0.05 & -0.02 \\
5. Contextual diversity block, all 11 variables & 0.10 & 0.01 & 0.01 & 0.03 & 1.00 & 1.00 \\
6. Contextual diversity block, select 8 variables & 0.09 & 0.02 & -0.02 & -0.01 & 0.89 & 1.00 \\
\hline
\end{tabular}

$\mathrm{N}=804$, correlations over 0.06 are significant at $\mathrm{p}<0.05$, correlations over 0.08 are significant at $\mathrm{p}<0.01$

The values above main diagonal (in italics) are corrected for unreliability attenuation 
Table 6. Multivariate OLS Regression, Personal and Contextual Diversity Blocks

\begin{tabular}{|c|c|c|c|c|c|c|c|c|c|c|}
\hline & \multicolumn{5}{|c|}{ Task outcomes } & \multicolumn{5}{|c|}{ Psychological Outcomes } \\
\hline & $\begin{array}{c}\text { Control } \\
\text { (1) }\end{array}$ & $\begin{array}{c}\text { Diversity } \\
\text { All } \\
\text { (2) }\end{array}$ & $\begin{array}{c}\text { Diversity } \\
\text { Select } \\
(3)\end{array}$ & $\begin{array}{c}\text { Full } \\
\text { All } \\
(4)\end{array}$ & $\begin{array}{l}\text { Full } \\
\text { Select } \\
(5)\end{array}$ & $\begin{array}{c}\text { Control } \\
(6)\end{array}$ & $\begin{array}{c}\text { Diversity } \\
\text { All } \\
(7)\end{array}$ & $\begin{array}{c}\text { Diversity } \\
\text { Select } \\
(8)\end{array}$ & $\begin{array}{c}\text { Full } \\
\text { All } \\
(9)\end{array}$ & $\begin{array}{l}\text { Full } \\
\text { Select } \\
(10)\end{array}$ \\
\hline Constant & $2.090 * *$ & $4.832 * *$ & $4.832 * *$ & 2.283 & $2.395 * *$ & $-0.031 * *$ & $3.906 * *$ & $3.906 * *$ & 0.162 & 0.239 \\
\hline Team size & -0.014 & & & -0.010 & -0.003 & $0.060 * *$ & & & $0.062 * *$ & $0.064 * *$ \\
\hline Percent male & $-0.428 * *$ & & & $-0.360 * *$ & $-0.364 * *$ & $-0.122 * *$ & & & $-0.105 * *$ & $-0.107 * *$ \\
\hline Avg. team age & $0.042 * *$ & & & $0.048 * *$ & $0.041 * *$ & $0.020 * *$ & & & $0.023 * *$ & $0.019 * *$ \\
\hline $\begin{array}{l}\text { Avg. international } \\
\text { experience }\end{array}$ & $0.035 * *$ & & & $0.035 * *$ & $0.039 * *$ & 0.011 & & & $0.012^{*}$ & $0.013^{*}$ \\
\hline Avg. technical skills & $0.386 * *$ & & & $0.327 * *$ & $0.332 * *$ & $0.493 * *$ & & & $0.440 * *$ & $0.442 * *$ \\
\hline $\begin{array}{l}\text { Avg. working language } \\
\text { skills }\end{array}$ & -0.014 & & & -0.061 & -0.062 & $0.131 * *$ & & & $0.126 * *$ & $0.129 * *$ \\
\hline Avg. cultural intelligence & $0.133^{*}$ & & & $0.143 * *$ & $0.136^{*}$ & $0.145^{* *}$ & & & $0.145 * *$ & $0.141 * *$ \\
\hline Personal Diversity & & $-0.315 * *$ & $-0.271 * *$ & $-0.139 * *$ & $-0.094 *$ & & $-0.312 * *$ & $-0.276 * *$ & $-0.076 * *$ & $-0.052 * *$ \\
\hline Contextual Diversity & & $0.107 * *$ & $0.076 * *$ & 0.042 & 0.035 & & 0.018 & 0.014 & 0.015 & 0.005 \\
\hline $\mathrm{R}^{2}$ & $0.071 * *$ & $0.040 * *$ & $0.045^{* *}$ & $0.075 * *$ & $0.076^{* *}$ & $0.383 * *$ & $0.149 * *$ & $0.180 * *$ & $0.387 * *$ & $0.386 * *$ \\
\hline
\end{tabular}

$* * \mathrm{p}<0.05, * \mathrm{p}<0.10, \mathrm{~N}=804$ 